Case Reports in
Gastroenterology
Case Rep Gastroenterol 2020;14:377-382

DOI: $10.1159 / 000508440$

Published online: July 28, 2020
(C) 2020 The Author(s)

Published by S. Karger AG, Basel www.karger.com/crg

This article is licensed under the Creative Commons Attribution-NonCommercial 4.0 International License (CC BY-NC) (http://www.karger.com/Services/OpenAccessLicense). Usage and distribution for commercial purposes requires written permission.

\title{
Anterior Cutaneous Nerve Entrapment Syndrome Occurring after Endoscopy
}

\author{
Takeshi Okamoto Katsuyuki Fukuda \\ Department of Gastroenterology, St. Luke's International Hospital, Tokyo, Japan
}

\section{Keywords}

Anterior cutaneous nerve entrapment syndrome · Abdominal pain · Endoscopy ·

Complications - Case report

\begin{abstract}
A 45-year-old lady presented for a follow-up endoscopy examination for mild abdominal pain due to gastric ulcers. She experienced a severe, markedly different type of pain with labor-like contractions 3 days later. Physical examination revealed tenderness confined to a $1 \times 1-\mathrm{cm}$ area and positive Carnett's sign. The pain completely resolved $10 \mathrm{~min}$ after a subcutaneous lidocaine injection. The patient was diagnosed with anterior cutaneous nerve entrapment syndrome. The pain returned within several hours and anterior neurectomy was performed several days later. The pain subsided immediately and no recurrence was seen during 3 years of followup.

\section{Introduction}

Anterior cutaneous nerve entrapment syndrome (ACNES) is a frequently overlooked cause of abdominal wall pain caused by entrapment of intercostal nerves. While John Carnett's 1926 article [1] led to the increased acceptance that pain can originate from the abdominal wall, ACNES remains underdiagnosed. Many reasons for this have been suggested, including omission from medical textbooks, the organ-based mindset of modern-day physicians, the 


\section{Case Reports in Gastroenterology}

Case Rep Gastroenterol 2020;14:377-382

DOI: $10.1159 / 000508440$

(c) 2020 The Author(s). Published by S. Karger AG, Basel www.karger.com/crg

Okamoto and Fukuda: Anterior Cutaneous Nerve Entrapment Syndrome after Endoscopy

inability to diagnose the condition on imaging studies, and the lack of specialists in abdominal wall pain [2]. Medical costs until diagnosis averaged USD 1,133 in one study [3] and can be as high as GBP 11,500 [4]. On the other hand, diagnosis and treatment are relatively straightforward once ACNES is included in the differential diagnosis. We present the case of a 45-yearold lady who was diagnosed with ACNES while being followed up for a different type of abdominal pain due to gastric ulcers. This is the first report of ACNES occurring after endoscopy.

\section{Case Presentation}

A 45-year-old lady presented to our department for evaluation of mild, dull epigastric pain. She had a history of rheumatoid arthritis, asthma, hypothyroidism, endometriosis, chronic kidney disease, anemia, and somatoform disorder. She had also received laparoscopic surgery several years prior for evaluation and treatment of infertility. She was taking 15 medications, including prednisolone ( $5 \mathrm{mg} /$ day), nonsteroidal anti-inflammatory drugs (NSAIDs), and a proton pump inhibitor. Joint pain had frequently led her to use more than three times the maximum allowable dose of NSAIDs, against advice from her rheumatologist.

Abdominal examination was unremarkable, with no abdominal tenderness. Esophagogastroduodenoscopy (EGD) revealed multiple shallow ulcers in the gastric antrum with no atrophic gastritis (Fig. 1a). She was diagnosed with drug-induced ulcers. The proton pump inhibitor was replaced with a potassium-competitive acid blocker and NSAIDs were discontinued. Some symptomatic relief was achieved. Three months later, the patient presented for follow-up EGD as her symptoms reappeared. Computed tomography of the abdomen taken in the meantime for other reasons was unremarkable. EGD (Fig. 1b) revealed an increase in gastric ulcers, which were again limited to the antrum. A double dose of the potassium-competitive acid blocker was prescribed.

Three days after the second EGD, the patient complained of severe epigastric pain with sharp, labor-like contractions. The pain was markedly different from the previous abdominal pain. It was aggravated by movement and persisted despite her taking acetaminophen tablets every $2 \mathrm{~h}$. Upon presentation, the patient was in severe distress, screaming and restless. Physical examination revealed severe tenderness confined to a $1 \times 1-\mathrm{cm}$ area on the left side of the rectus abdominis, $3 \mathrm{~cm}$ caudal to the costal arch. No masses were palpated. Diminished pain and temperature sensation were noted in a $2 \times 4-\mathrm{cm}$ area surrounding the area of localized tenderness. Carnett's sign was positive. Laboratory results revealed anemia, lymphocytopenia, and elevated creatinine consistent with the patient's baseline values. White blood cells and $\mathrm{C}$-reactive protein were within the normal range. Cytomegalovirus antigenemia titer was negative.

After intravenous analgesics had proved futile, a 10 -mL subcutaneous injection of $1 \%$ lidocaine was made to the point of maximal pain. The pain completely resolved within 10 min. The patient was diagnosed with ACNES, most likely affecting the 8th left intercostal nerve. The pain resumed several hours later. A $10-\mathrm{mL}$ subcutaneous injection with steroids added to $1 \%$ lidocaine was tried, which also only provided relief until the next morning. Plastic surgeons were consulted and an anterior neurectomy was performed 12 days after the onset of ACNES. The sharp pain subsided immediately after surgery. When the initial dull epigastric pain returned the next month, follow-up EGD (Fig. 1c) revealed healing ulcers. Functional dyspepsia was suspected and medications were adjusted accordingly. Abdominal pain resolved completely within 3 months after surgery. Follow-up EGD 5 months after surgery (Fig. 1d) 


\section{Case Reports in Gastroenterology}

Case Rep Gastroenterol 2020;14:377-382

DOI: $10.1159 / 000508440$

( 2020 The Author(s). Published by S. Karger AG, Basel www.karger.com/crg

Okamoto and Fukuda: Anterior Cutaneous Nerve Entrapment Syndrome after Endoscopy

confirmed that the gastric ulcers had healed completely, leaving ulcer scars. No recurrence of either type of abdominal pain was seen during 3 years of follow-up.

\section{Discussion}

ACNES is the most common form of abdominal wall pain caused by benign entrapment of intercostal nerves. Abdominal wall pain can be caused by various etiologies including hernias, endometriosis, and slipping rib syndrome, arise after abdominal surgery, or be referred from intra-abdominal visceral pathologies [5]. Abdominal pain generally presents with isolated focal pain with normal findings on laboratory and imaging tests. There is one report which suggests a potential role of ultrasound or magnetic resource imaging in the diagnosis of ACNES [6], and further studies are warranted in this area.

In a study of 1,116 patients by Mol et al. [7], ACNES was 3.7 times more common in females. While the median age was 42 years, ACNES has been reported in children as well as octogenarians. About half experience sudden-onset pain, which can arise from any of the lower intercostal nerves but is most common in the right lower quadrant. The area of pain can be very limited, often to the area of one finger. Local somatosensory abnormalities surrounding the point of maximum pain are seen in $78 \%$ of patients. Bilateral pain is reported in $13 \%$ of cases [8].

Positive Carnett's sign, characterized by increased tenderness with increased abdominal tension, is observed in about $87 \%$ of ACNES patients. While Carnett's sign was also positive in $86 \%$ of patients with psychogenic abdominal pain in one study [9], pain reduction after trigger point injection with lidocaine can differentiate between the two entities. Interestingly, 1 of 6 patients with gastric ulcers also tested positive for Carnett's sign in the same study.

Common comorbidities in an American study [3] included obesity/overweight (83.9\%), functional gastrointestinal disorders (33.9\%), chronic low back pain (30.1\%), and gastroesophageal reflux disease (27.1\%). Treatment generally begins with trigger point injections, which also assist in reaching a diagnosis. Dutch randomized controlled trials demonstrated a benefit of $1 \%$ lidocaine trigger point injections over placebo [10], no additional benefit from adding steroids to lidocaine [11], and effectiveness of open surgical neurectomy for pain refractory to trigger point injections [12].

In our case, the patient had two distinct causes of epigastric pain. This can make the diagnosis of ACNES a greater hurdle, as experienced by Lam and Vasey [13] in a case of ACNES arising in a Crohn's disease patient. Given the patient's history of somatoform disorder, psychogenic abdominal pain and functional dyspepsia were also in our differential. Physical examination including positive Carnett's sign allowed us to narrow our differential to ACNES and psychogenic pain, while the trigger point injection led us to our final diagnosis of ACNES.

The etiology of ACNES in our patient also presented a challenge. While more than half of ACNES cases arise spontaneously, other known triggers include recent abdominal surgery, abdominal trauma, exercise, pregnancy, and influenza [7]. A case of ACNES thought to be triggered by oral contraceptives has also been reported [14]. While our patient had a history of laparotomy several years earlier, the delay of only 3 days between EGD and onset of ACNES led us to suspect endoscopy as a trigger for ACNES. All known triggers are associated with increased pressure on the abdominal wall and endoscopy fits this rule perfectly. 


\section{Case Reports in Gastroenterology}

\section{Conclusion}

We report the first case of ACNES occurring after endoscopy. It is unclear whether endoscopy triggered ACNES in this case, but physicians should be alerted to this possibility. A high index of suspicion is required for the diagnosis of ACNES. Rapid diagnosis can reduce unnecessary testing and allow for early treatment of this often overlooked and debilitating disease.

\section{Statement of Ethics}

The patient gave her written informed consent for publication of her case (including publication of images). The identity of the patient has been protected.

\section{Conflict of Interest Statement}

The authors have no conflicts of interest to declare.

\section{Funding Sources}

None.

\section{Author Contributions}

T. Okamoto wrote the manuscript, diagnosed the patient, and performed the endoscopic procedures. K. Fukuda edited the manuscript. Both authors gave final approval of the manuscript.

\section{References}

1 Carnett JB. Intercostal neuralgia as a cause of abdominal pain and tenderness. Surg Gynecol Obstet. 1926;42: 625-32.

2 Scheltinga MR, Roumen RM. Anterior cutaneous nerve entrapment syndrome (ACNES). Hernia. 2018 Jun; 22(3):507-16.

3 Costanza CD, Longstreth GF, Liu AL. Chronic abdominal wall pain: clinical features, health care costs, and long-term outcome. Clin Gastroenterol Hepatol. 2004 May;2(5):395-9.

4 Dancer SJ, Macpherson SG, de Beaux AC. Protracted diagnosis of ACNES: a costly exercise. J Surg Case Rep. 2018 Sep;2018(9):rjy 230.

5 Shian B, Larson ST. Abdominal Wall Pain: Clinical Evaluation, Differential Diagnosis, and Treatment. Am Fam Physician. 2018 Oct;98(7):429-36.

6 Guedes-Correa JF, de Bulhões SO. Abdominal cutaneous nerve entrapment syndrome, case report and diagnostic evaluation. Arq Bras Neurocir. 2019;38(2):141-4.

7 Mol FM, Maatman RC, De Joode LE, Van Eerten P, Scheltinga MR, Roumen R. Characteristics of 1116 consecutive patients diagnosed with anterior cutaneous nerve entrapment syndrome (ACNES). Ann Surg. doi: 10.1097/SLA.0000000000003224 [Epub ahead of print].

8 Maatman RC, Werner MU, Scheltinga MR, Roumen RM. Bilateral distribution of anterior cutaneous nerve entrapment syndrome (ACNES): are clinical features and outcomes comparable to unilateral ACNES? Reg Anesth Pain Med. 2019 Jan;44(4):rapm-2018-100062.

9 Takada T, Ikusaka M, Ohira Y, Noda K, Tsukamoto T. Diagnostic usefulness of Carnett's test in psychogenic abdominal pain. Intern Med. 2011;50(3):213-7. 
Case Reports in Gastroenterology
Case Rep Gastroenterol 2020;14:377-382

DOI: $10.1159 / 000508440$

(c) 2020 The Author(s). Published by S. Karger AG, Basel www.karger.com/crg

Okamoto and Fukuda: Anterior Cutaneous Nerve Entrapment Syndrome after Endoscopy

10 Boelens OB, Scheltinga MR, Houterman S, Roumen RM. Randomized clinical trial of trigger point infiltration with lidocaine to diagnose anterior cutaneous nerve entrapment syndrome. Br J Surg. 2013 Jan;100(2):21721.

11 Mol FM, Jansen CH, Boelens OB, Stronks DL, Eerten PV, Huygen FJ, et al. Adding steroids to lidocaine in a therapeutic injection regimen for patients with abdominal pain due to anterior cutaneous nerve entrapment syndrome (ACNES): a single blinded randomized clinical trial. Scand J Pain. 2018 Jul;18(3):505-12.

12 Boelens OB, van Assen T, Houterman S, Scheltinga MR, Roumen RM. A double-blind, randomized, controlled trial on surgery for chronic abdominal pain due to anterior cutaneous nerve entrapment syndrome. Ann Surg. 2013 May;257(5):845-9.

13 Lam K, Vasey C. Diagnostic dilemma: think about anterior cutaneous nerve entrapment syndrome (ACNES) in patients with atypical abdominal pain and Crohn's disease. BMJ Case Rep. 2018 Mar;2018: bcr2017224041.

14 Peleg R. Abdominal wall pain caused by cutaneous nerve entrapment in an adolescent girl taking oral contraceptive pills. J Adolesc Health. 1999 Jan;24(1):45-7. 
Case Reports in Gastroenterology
Case Rep Gastroenterol 2020;14:377-382

DOI: $10.1159 / 000508440$

(c) 2020 The Author(s). Published by S. Karger AG, Basel www.karger.com/crg

Okamoto and Fukuda: Anterior Cutaneous Nerve Entrapment Syndrome after Endoscopy
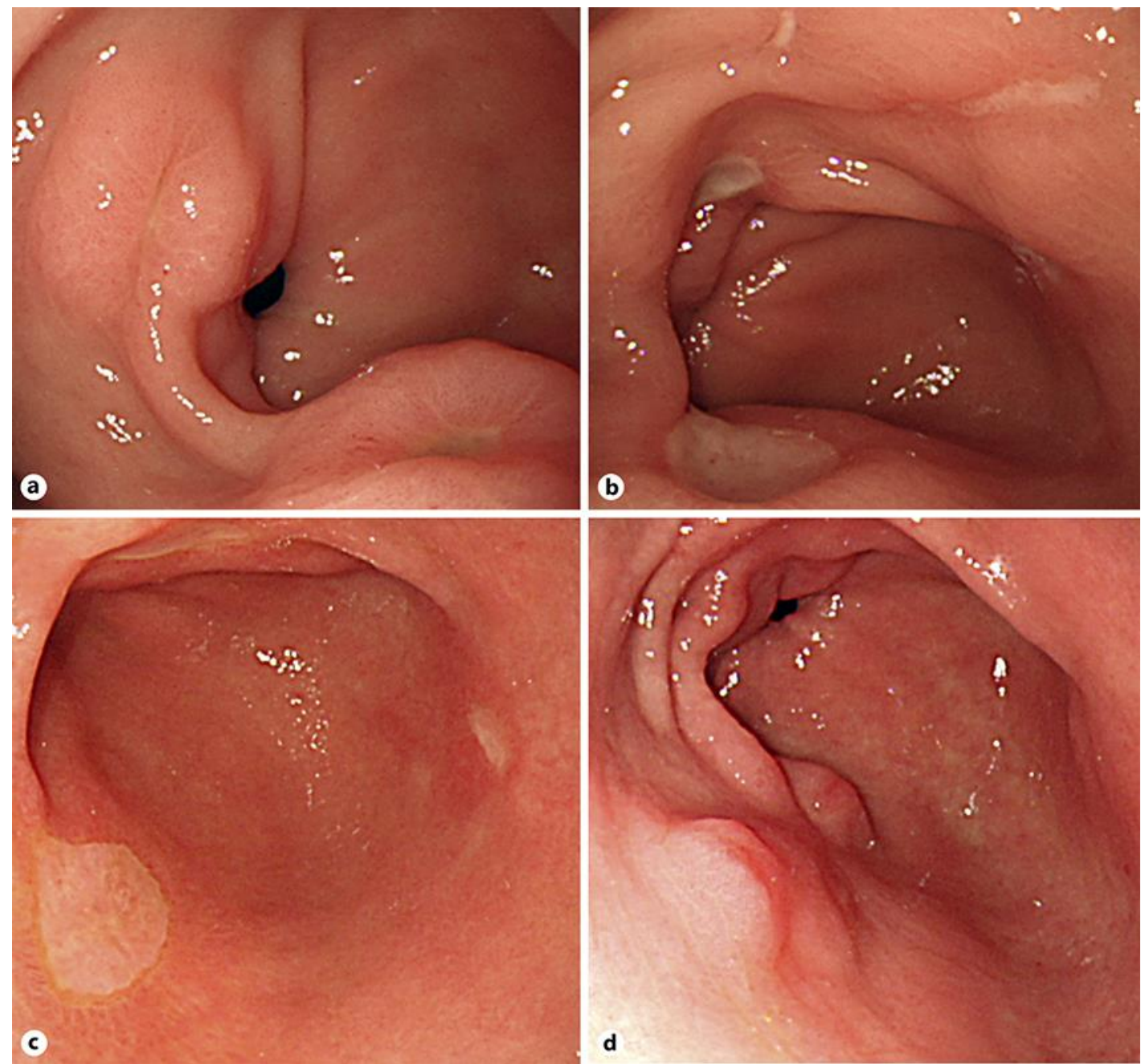

Fig. 1. Endoscopic view of the gastric antrum 3 months before onset of ACNES, with multiple drug-induced ulcers (a), 3 days before onset, with an increase in ulcers (b), 1 month after neurectomy, with shallow, healing ulcers (c), and 5 months after neurectomy, with ulcer scar formation (d). ACNES, anterior cutaneous nerve entrapment syndrome. 